\title{
The Kangding earthquake swarm of November, 2014
}

\author{
Wen Yang $\cdot$ Jia Cheng $\cdot$ Jie Liu $\cdot$ Xuemei Zhang
}

Received: 9 April 2015/ Accepted: 19 May 2015/Published online: 16 June 2015

(C) The Author(s) 2015. This article is published with open access at Springerlink.com

\begin{abstract}
There was an earthquake swarm of two major events of $M_{\mathrm{S}} 6.3$ and $M_{\mathrm{S}} 5.8$ on the Xianshuihe fault in November, 2014. The two major earthquakes are both strike-slip events with aftershock zone along NW direction. We have analyzed the characteristics of this earthquake sequence. The $b$ value and the $h$ value show the significant variations in different periods before and after the $M_{\mathrm{S}} 5.8$ earthquake. Based on the data of historical earthquakes, we also illustrated the moderate-strong seismic activity on the Xianshuihe fault. The Kangding earthquake swarm manifests the seismic activity on Xianshuihe fault may be in the late seismic active period. The occurrence of the Kangding earthquake may be an adjustment of the strong earthquakes on the Xianshuihe fault. The Coulomb failure stress changes caused by the historical earthquakes were also given in this article. The results indicate that the earthquake swarm was encouraged by the historical earthquakes since 1893 , especially by the $M_{\mathrm{S}} 7.5$ Kangding earthquake in 1955. The Coulomb failure stress changes also shows the subsequent $M_{\mathrm{S}} 5.8$ earthquake was triggered by the $M_{\mathrm{S}} 6.3$ earthquake.
\end{abstract}

Keywords Kangding earthquake swarm of 2014 . Xianshuihe fault $\cdot$ Seismic activity $\cdot$ Coulomb failure stress change

W. Yang $\cdot$ J. Cheng $\cdot$ J. Liu $(\bowtie) \cdot X$. Zhang

China Earthquake Networks Center, Beijing 100045, China

e-mail: yangwen@seis.ac.cn

J. Cheng

Institute of Geology, China Earthquake Administrator,

Beijing 100029, China

\section{Introduction}

According to the determination of China Earthquake Networks Center (2014), the Kangding $M_{\mathrm{S}} 6.3$ earthquake occurred at 16:55 pm on November 22th, 2014. A few days later, another earthquake whose magnitude is $M_{\mathrm{S}} 5.8$ hit at 23:19 pm on November 25th, 2014. The two earthquakes were about $10 \mathrm{~km}$ away from each other. The epicenter of the $M_{\mathrm{S}} 6.3$ earthquake was $40 \mathrm{~km}$ away from Kangding county $\left(30.3^{\circ} \mathrm{N}, 101.7^{\circ} \mathrm{E}\right)$ with depth of $18 \mathrm{~km}$. And the epicentral location of $M_{\mathrm{S}} 5.8$ shock was $30.2^{\circ} \mathrm{N}, 101.7^{\circ} \mathrm{E}$ with focal depth of $16 \mathrm{~km}$ (http://www.ceic.ac.cn/speedsearch?time= 10). USGS (2014) gave the epicenter of the two earthquakes were $30.340^{\circ} \mathrm{N}, 101.737^{\circ} \mathrm{E}$ and $30.188^{\circ} \mathrm{N}, 101.762^{\circ} \mathrm{E}$, respectively (http://earthquake.usgs.gov/earthquakes). The depths of the two earthquakes they gave are about $9 \mathrm{~km}$. Most of the strong earthquakes on Xianshuihe fault are of main shock-after shock type. However, there were two earthquake swarms including this one on Xianshuihe fault since 1970. The two earthquakes are both located on the Holocene fault named Selaha fault segment which is between Kangding and Qianning regions on the Xianshuihe fault. The consistency in the focal mechanisms of the $M_{\mathrm{S}} 6.3$ and $M_{\mathrm{S}} 5.8$ earthquakes manifests the particularity of the earthquake swarm.

Since the Wenchuan $M_{\mathrm{S}} 8.0$ earthquake in 2008 , the seismicity of the southeastern Bayan Har blocks is significant. It is followed by the Yushu $M_{\mathrm{S}} 7.1$ earthquake on 14 April 2010, the Lushan $M_{\mathrm{S}} 7.0$ earthquake on 20 April 2014, and the Kangding $M_{\mathrm{S}} 6.3$ earthquake on 22 November 2014 successively. The Kangding earthquake is also the first strong earthquake above $M_{\mathrm{S}} 6.0$ in Xianshuihe fault since Daofu $M_{\mathrm{S}} 6.9$ earthquake on 24 January 1981 . The active strong earthquakes on the Xianshuihe fault is a noteworthy phenomenon. 
The China Earthquake Administrator (CEA) launched the emergency response at the first time after the Kangding earthquake. Many earthquake parameters have been provided by the CEA to analyze the seismic hazard, which are concerned for studying the mechanism of the Kangding earthquake swarm and the seismic hazard on the Xianshuihe fault. We studied on the tectonic setting of Xianshuihe fault and the characteristics of the Kangding sequence. We also discussed the migration of the moderate-strong earthquakes and the Coulomb failure stress change around the Xianshuihe fault to find the seismic hazard on Xianshuihe fault in future.

\section{Tectonic setting of Xianshuihe fault and historical earthquakes}

The epicenter of the $M_{\mathrm{S}} 6.3$ Kangding earthquake on 22 November 2014 is located on the sinistral slip Xianshuihe fault which is in the southeastern margin of the Tibetan plateau. The Xianshuihe fault starts at Garzê in northwest, and crosses Luhuo, Daofu, Qianning, Kangding to Luding region in southeast. The strike of the faults is NW in the north of Kangding and converts to NNW in the south which exhibit slightly curved towards NE (Tang and Huang 1983). The Xianshuihe fault is the boundary fault between the Bayan Har block and the Qiangtang block, with sinistral slip rate of about $12 \mathrm{~mm} / \mathrm{a}$ (Allen et al. 1991; Xu et al. 2003; Zhang et al. 2003; Gan et al. 2007). Due to the continuous compression from the Indian plate, the crustal motion of the central Tibetan plateau behaves as the high speed eastward extrusion and also causes frequently strong earthquakes. The Bayan Har block, surrounded by the sinistral Eastern Kunlun fault in the north, the sinistral Altyn Tagh fault in the west, the sinistral Manyi-YushuXianshuihe fault in the south, and the thrust Longmenshan fault in the east, is the most active block in Tibetan plateau in recent 20 years (Deng et al. 2010; Cheng et al. 2011a). Since the Manyi $M_{\mathrm{S}} 7.5$ earthquake in 1997, all the earthquakes with magnitude larger than $M_{\mathrm{S}} 7.0$ in the Chinese mainland, including the Manyi $M_{\mathrm{S}} 7.5$ earthquake in 1997, the Hoh Xil $M_{\mathrm{S}} 8.1$ earthquake in 2001, the Yutian $M_{\mathrm{S}} 7.3$ earthquake in 2008 , the Wenchuan $M_{\mathrm{S}} 8.0$ earthquake in 2008, the Yushu $M_{\mathrm{S}} 7.1$ earthquake in 2010, the Lushan $M_{\mathrm{S}} 7.0$ earthquake in 2013 , and the $M_{\mathrm{S}} 7.3$ Yutian earthquake in 2014, have concentrated on the boundary faults around the Bayan Har block. The focal mechanisms of these earthquakes also show the whole eastward motion of the Bayan Har block, the sinistral slip motion on the eastern Kunlun fault and Manyi-Yushu-Xianshuihe fault, the normal slip on the south end of the Altyn Tagh fault, and the thrust on the Longmenshan fault. And the boundary faults of the Bayan Har block are still able to nurture strong earthquakes in the near future, especially on the fault segments with no recent large earthquakes.

Among the boundary faults of the Bayan Har block, the Xianshuihe faults are the most active one with tens of historical earthquakes larger than $M 7.0$ on its $300 \mathrm{~km}$

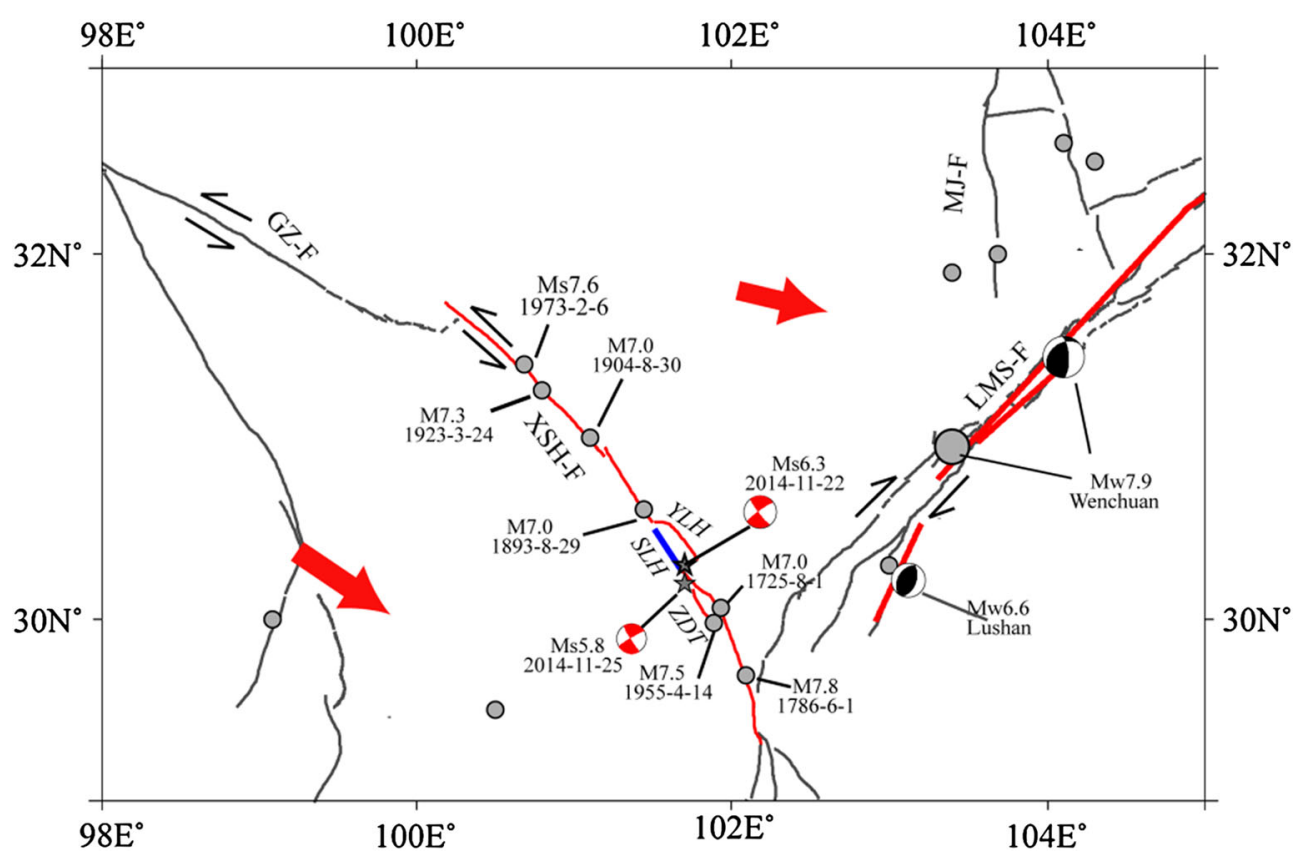

Fig. 1 Historical earthquakes on the Xianshuihe fault. Gray lines are the active faults. Gray circles are the historical earthquakes larger than M7. Red lines show the ruptured segments of the historical earthquakes. Beach balls are the focal mechanisms of the recent large earthquakes. GZ-F, the Garze fault; XSH-F, the Xianshuihe fault; LMS-F, the Longmenshan fault; MJ-F, the Minjiang fault 
length (Fig. 1) (Wen 1989, 2000; Wen et al. 2008; Allen et al. 1991; Xu et al. 2003; Cheng et al. 2011a). Since 1700, almost all the segments of the fault have been ruptured by strong earthquakes, including the Luhuo $M_{\mathrm{S}} 7.6$ earthquake in 1973, the Renda $M 7.3$ earthquake in 1923, the Daofu $M 7.0$ earthquake in 1904, the Qianning $M 7.0$ earthquake in 1893 , the Kangding $M 7.0$ earthquake in 1725 , the Kangding M7.5 earthquake in 1955, and the M7.8 Kangding earthquake in 1786 , with the $40 \mathrm{~km}$ length northern segment of the Selaha fault, not struck by considerable earthquake. The Selaha fault segment is in the section where the Xianshuihe fault is consisted by three fault branches, the Selaha fault, the Yalahe fault, and the Zheduotang fault. The Yalahe fault is stuck by an M6-7 earthquake in 1700, while the southern segment of Selaha fault and the Zheduotang fault was ruptured by the Kangding M7.0 earthquake in 1725 and the Kangding M7.5 earthquake in 1955, respectively (Wen 2000; Wen et al. 2008; Cheng et al. 2011a).

From the located epicenter of the earthquakes, the Kangding $M_{\mathrm{S}} 6.3$ earthquake on 22 November 2014 was on the northern segment of the Selaha fault, which did not rupture the $40 \mathrm{~m}$ length. While Kangding $M_{\mathrm{S}} 5.8$ earthquake on 25 November 2014 was on the end portion of the Zheduotang fault. The two recent earthquakes on the adjacent fault branch with distance nearly $10 \mathrm{~km}$ and their similar focal mechanisms attract us on studying the characters of the Xianshuihe fault.

\section{Characteristics of the Kangding earthquake sequence}

According to the results of China Earthquake Networks Center, the scalar seismic moment of the Kangding $M_{\mathrm{S}} 6.3$ and $M_{\mathrm{S}} 5.8$ earthquakes was $1.14 \times 10^{18}$ and $2.16 \times 10^{17} \mathrm{~N}$ m. The strike, dip, and rake of the Kangding $M_{\mathrm{S}} 6.3^{\prime} \mathrm{s}$ focal mechanism are $145^{\circ} / 78^{\circ} /-11^{\circ}$, respectively, and the auxiliary nodal plane solution is $237^{\circ} / 79^{\circ} /-168^{\circ}$. The two nodal planes of the $M_{\mathrm{S}} 5.8$ event are $152^{\circ}$ $80^{\circ} /-10^{\circ}$ and $244^{\circ} / 80^{\circ} /-170^{\circ}$, very similar to the mainshock. The two earthquakes are both strike-slip events, reflecting the sinistral dislocation characteristics of the Xianshuihe fault at the tectonic stress field in nearly EW direction.

According to the earthquake catalog provided by Sichuan Regional Seismic Networks, 1026 earthquakes were recorded before 24:00 pm on December 2, 2014. There are 317 earthquakes with $M_{\mathrm{L}} 0.0-0.9,633$ earthquakes with $M_{\mathrm{L}} 1.0-1.9,67$ earthquakes with $M_{\mathrm{L}} 2.0-2.9$, and seven earthquakes with $M_{\mathrm{L}} 3.0-3.9$; the epicenter distribution is shown in Fig. 2a. As shown in Fig. 2b, the aftershock zone before and after the $M_{\mathrm{S}} 5.8$ earthquake both extend along the NW direction. And the length of the
$M_{\mathrm{S}} 6.3$ 's aftershock zone above is about $25 \mathrm{~km}$, while the length of the $M_{\mathrm{S}} 5.8$ 's is about $14 \mathrm{~km}$. The whole aftershock zone distributes with major axis of around $47 \mathrm{~km}$ and the minor axis of around $13 \mathrm{~km}$. It indicates that the two strong earthquakes may be controlled by the same fault branch.

Figure 3 shows that the aftershocks above $M_{\mathrm{L}} 2.0$ of the $M_{\mathrm{S}} 6.3$ earthquake sequence are not abundant, there are only four earthquakes above $M_{\mathrm{L}} 3.0$ occurred between the $M_{\mathrm{S}} 6.3$ earthquake and the $M_{\mathrm{S}} 5.8$ earthquake, including three earthquakes within $24 \mathrm{~h}$ after the main shock. There were no earthquakes above $M_{\mathrm{L}} 2.0$ one day before the $M_{\mathrm{S}} 5.8$ earthquake. The aftershocks decay gradually after the $M_{\mathrm{S}} 5.8$ earthquake. The lack of moderate earthquakes is a significant phenomenon before the strong aftershocks (Wang and Wang 1983). It may be related to the energy accumulating during the quiet period.

The $b$ value of this earthquake swarm is calculated which is important for estimating seismic hazard. The $b$ value of the Kangding $M_{\mathrm{S}} 6.3$ is about 0.89 between the $M_{\mathrm{S}} 6.3$ earthquake and the $M_{\mathrm{S}} 5.8$ earthquake, which is lower than the average $b$ value of the Xianshuihe fault zone 0.99 (from 2000 to 2014) (Fig. 4). It indicates that the stress of the region was still high during this period. When the Kangding $M_{\mathrm{S}} 5.8$ earthquake occurred on November 25 , the $b$ value rise up to 1.14 , indicating the lower stress level in the region and the stress relaxation after the second earthquake is more than the first one.

The $h$ value is a parameter to describe the decay of the aftershock's frequency in seismology (Omori 1894; Utsu 1961; Mogi 1962). We used the modified Omori's formula to study the decay of the aftershocks.

$n(t)=n_{1} t^{-h}$,

where $n(t)$ is the aftershocks' frequency in the $t$ th day after the mainshock, $n_{1}$ is the aftershocks' frequency in the first day after the mainshock, and $h$ is the decay coefficient.

The $h$ values are both greater than 1.0 (Fig. 5) before and after the $M_{\mathrm{S}} 5.8$ earthquake. However, the $h$ value after the $M_{\mathrm{S}} 6.3$ earthquake (1.55) was greater than the $h$ value after the $M_{\mathrm{S}} 5.8$ earthquake (1.31). This shows that the aftershocks of the $M_{\mathrm{S}} 6.3$ earthquake decayed more rapidly than the aftershocks of the $M_{\mathrm{S}} 5.8$ earthquake.

From Fig. 6, the aftershock zone extended to both sides with length of $25 \mathrm{~km}$ in the early few hours after the $M_{\mathrm{S}} 6.3$ Kangding earthquake. And the aftershock's distribution of the main shock is more intensive in northwest than that in southeast. Subsequently, the aftershock's activity weakened in the northwest before the $M_{\mathrm{S}} 5.8$ earthquake. The $M_{\mathrm{S}} 5.8$ earthquake occurred when the aftershocks gradually concentrated in southeast. From then on, the aftershock activity is mainly in the vicinity of the $M_{\mathrm{S}} 5.8$ earthquake and in the northwestern region of the $M_{\mathrm{S}} 6.3$ earthquake. 


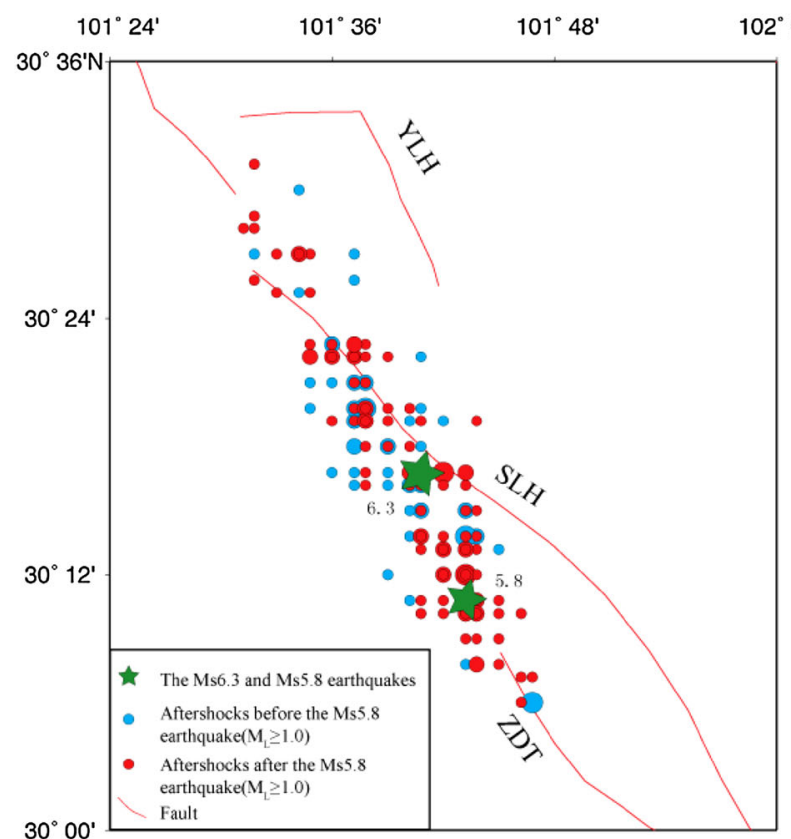

(a)

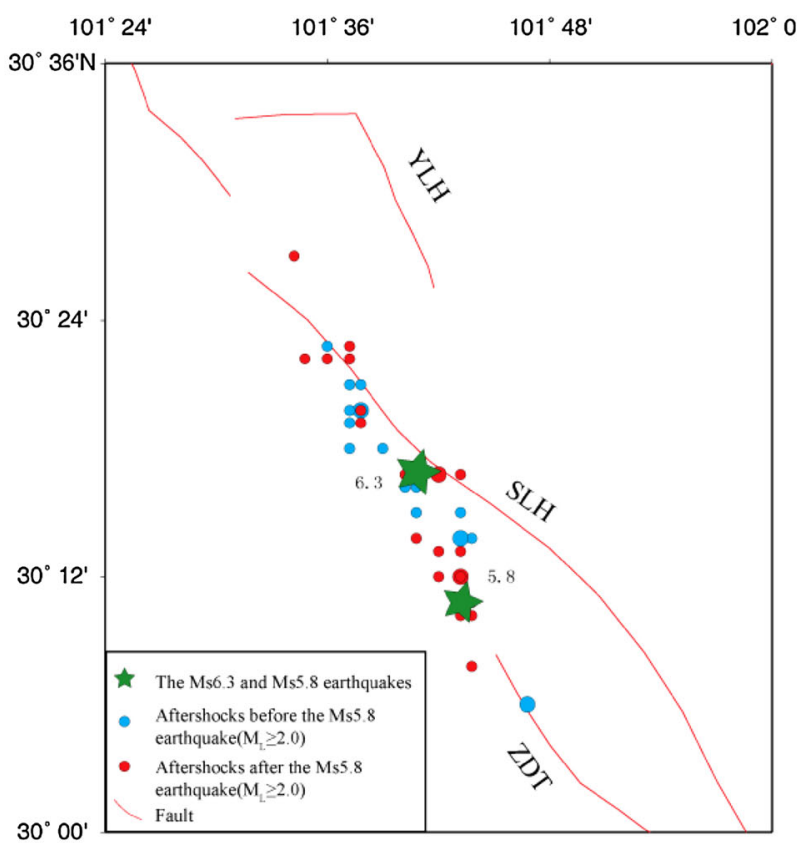

(b)

Fig. 2 Distribution of the aftershock of the $M_{\mathrm{S}} 6.3$ Kangding earthquake. a The aftershock above $M_{\mathrm{L}} 1.0$. b the aftershock above $M_{\mathrm{L}} 2.0$. The blue circle represents the earthquakes before the $M_{\mathrm{S}} 5.8$ earthquake, while the red one represents the aftershocks after the $M_{\mathrm{S}} 5.8$ earthquake. The red lines represent the fault branch of Xianshuihe fault. YLH, the Yalahe branch fault; SLH, the Selaha branch fault; ZDT, the Zheduotang branch fault

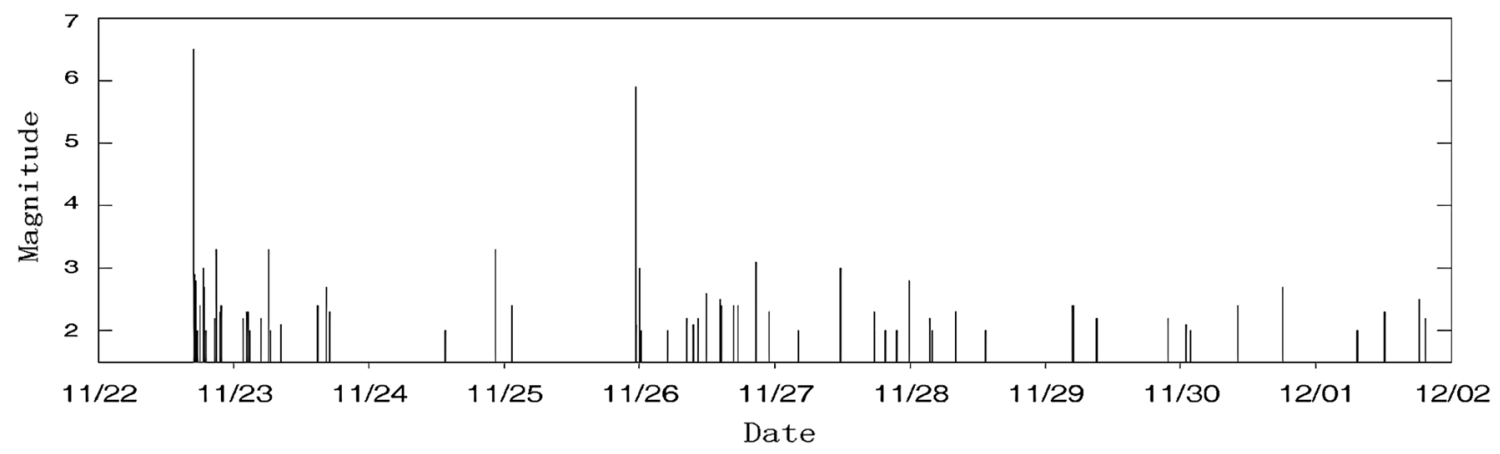

Fig. 3 The $M$ - $t$ figure of the $M_{\mathrm{S}} 6.3$ earthquake sequence above $M_{\mathrm{L}} 2.0$

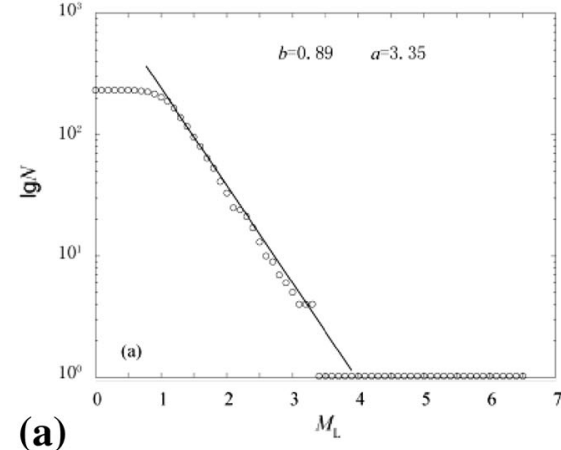

(a)

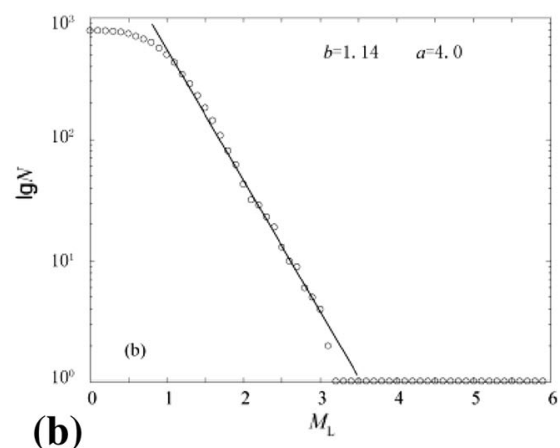

(b)

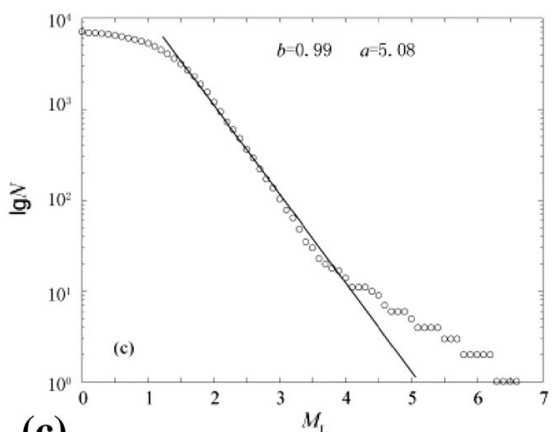

(c)

Fig. $4 b$ value in different periods a between the $M_{\mathrm{S}} 5.8$ earthquake and the $M_{\mathrm{S}} 6.3$ earthquake, $\mathbf{b}$ after the $M_{\mathrm{S}} 5.8$ earthquake, $\mathbf{c}$ average $b$ value on Xianshuihe fault (from 2000 to 2014) 


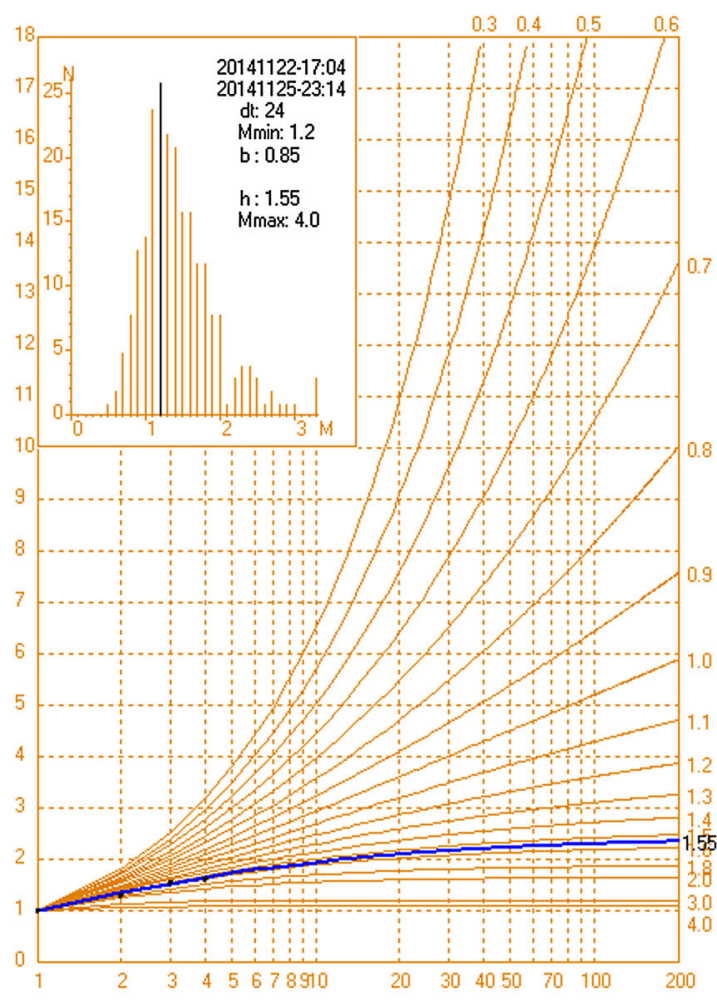

(a)

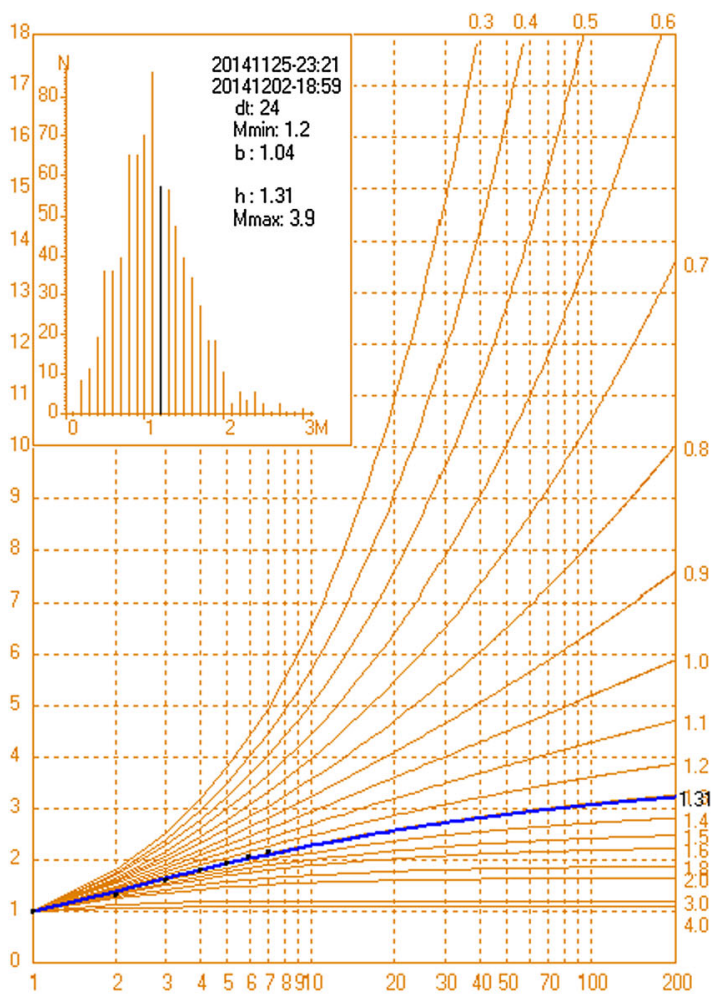

(b)

Fig. $5 h$ value in different periods a Before $M_{\mathrm{S}} 5.8$ earthquake and after $M_{\mathrm{S}} 6.3$ earthquake b After $M_{\mathrm{S}} 5.8$ earthquake

The $M_{\mathrm{S}} 5.8$ earthquake and the subsequent aftershocks make the aftershock zone extended to $47 \mathrm{~km}$. During the later period, the aftershock near the main shock was scarce, indicating the vicinity of the $M_{\mathrm{S}} 6.3$ earthquake ruptured completely.

\section{Characteristics of historical earthquakes on Xianshuihe fault}

Figure 7a shows the occurrence times of earthquakes above $M_{\mathrm{S}} 6.0$ on Xianshuihe fault since 1700 . It can be seen that the strong earthquakes on Xianshuihe fault occurred frequently since 1893 , there were 13 earthquakes above $M_{\mathrm{S}} 6.0$ in which 5 earthquakes above $M_{\mathrm{S}} 7.0$ and the latest $M_{\mathrm{S}} 7.0$ earthquake is the Luhuo $M_{\mathrm{S}} 7.6$ earthquake on 6 February 1973.

There were no earthquakes above $M_{\mathrm{S}} 6.0$ occurred on Xianshuihe fault for 33 years before the November 22, 2014 Kangding $M_{\mathrm{S}} 6.3$ earthquake. However, compared with the year 1816 to year 1893 , the prolonged quiescence period was not the longest. The seismic activity since 1700 can be divided into two active periods. The first seismic active period was from year 1725 to year 1816 . The second seismic active period started from year 1893. Although the
33 years' quiescence period was not a short time, it was much shorter than the nearly 80 years' quiescence period between the two active periods. Therefore, we think the occurrence of the Kangding earthquake swarm indicates the adjustment in relative inactive period. It may be relative with the Wenchuan earthquake and Lushan earthquake occurred in Longmenshan fault recently. The new seismic active period on Xianshuihe fault may come in advance.

The Kangding $M_{\mathrm{S}} 6.3$ earthquake happened in the southeast of the earthquake gap in the Xianshuihe fault (Han and Huang 1983). Its epicenter is between the 29 August 1893 Daofu $M_{\mathrm{S}} 7.0$ earthquake and the 14 April 1955 Kangding $M_{\mathrm{S}} 7.5$ earthquake. The earthquake gap is regarded as the area where the great earthquake would happen (Han and Huang 1983; Lin et al. 1986). However, this Kangding earthquake swarm had no impact on the earthquake gap. This swarm may be a signal. The earthquake stress transfer can just encourage the earthquake occurrence, but cannot easily induce fault active.

The Xianshuihe fault can be divided into the southeast and northwest segment by the earthquake gap. The earthquakes above $M_{\mathrm{S}} 6.0$ occurred alternately in the southeast and the northwest part of the Xianshuihe fault, as shown in Fig. 7b. In addition, the area of earthquakes tends to extend to both ends of the Xianshuihe fault. The earthquakes 


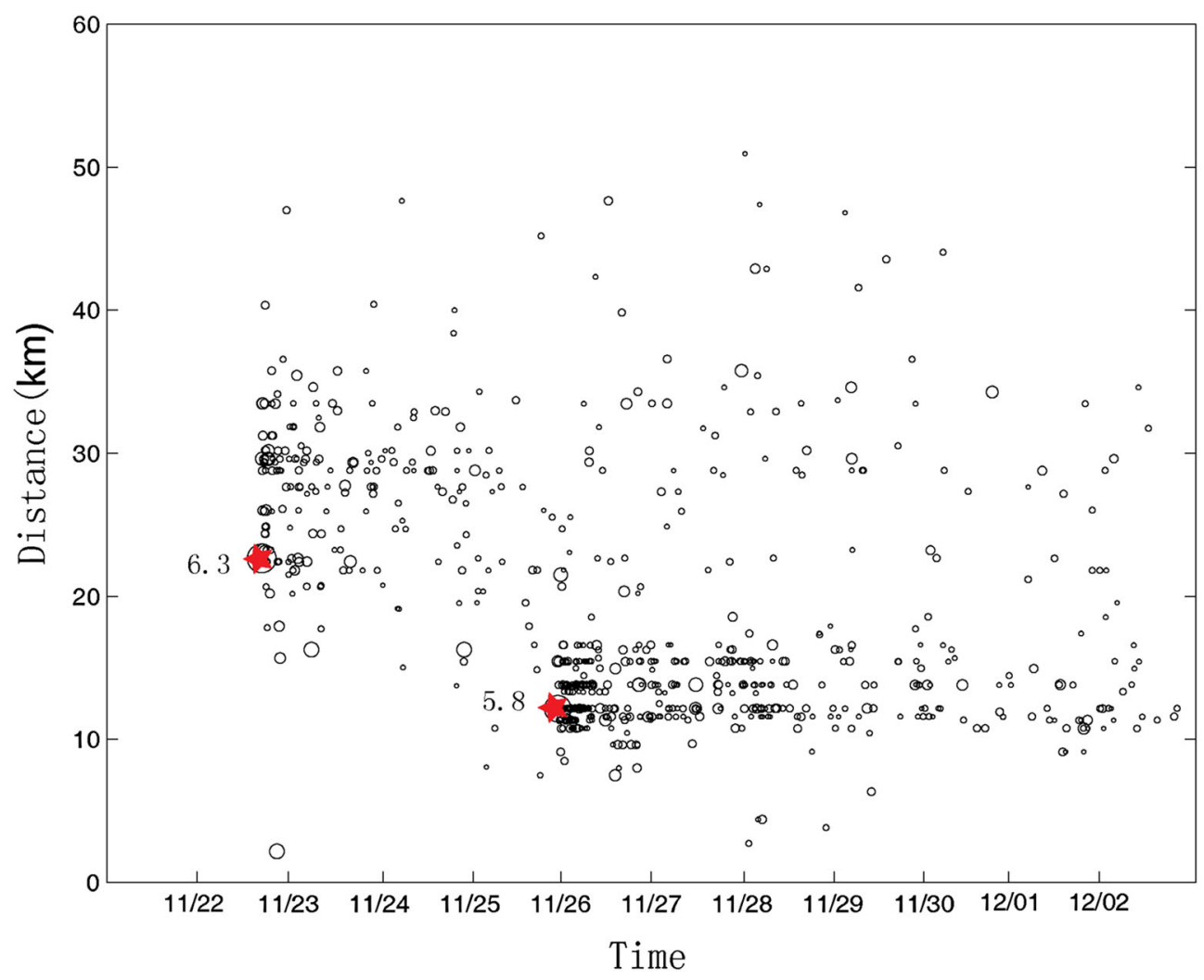

Fig. 6 The occurrence times of aftershocks since the $M_{\mathrm{S}} 6.3$ Kangding earthquake versus the distances along strike. The small star indicates the $M_{\mathrm{S}} 6.3$ and $M_{\mathrm{S}} 5.8$ earthquake, respectively $\left(M_{\mathrm{L}} \geq 1.0\right)$

above $M_{\mathrm{S}} 6.0$ in the southeast were significantly less active than that in the northwest.

We also analyze the modern earthquakes above $M_{\mathrm{L}} 4.0$ since 1970. Figure 8 shows that the moderate earthquakes in the westnorthern Xianshuihe fault were very active in the early 1970s. Several months before the $M_{\mathrm{S}} 7.6$ Luhuo earthquake in 1973 , there was a $M_{\mathrm{S}} 5.0$ earthquake swarm near the Kangding region in September 1972. Then, the earthquakes above $M_{\mathrm{L}} 4.0$ were scarce from 1974 to 1981 . Subsequently, the $M_{\mathrm{S}} 6.9$ earthquake hit in Daofu region on 24 January 1981. After that, there were a few earthquakes on Xianshuihe fault until 2000. In particular, there were no earthquakes above $M_{\mathrm{L}} 4.0$ on the whole Xianshuihe fault from 1990 to 2000. Since 2000, the moderate earthquakes migrated from northwest to the southeast segment along the Xianshuihe fault until the $M_{\mathrm{S}} 6.3$ Kangding earthquake happened. These reflect the alternate activity of the strong and weak earthquakes on the Xianshuihe fault. It also indicates the enhance seismicity on the southeast segment of the Xianshuihe fault. Due to the adjustment of the strong earthquake, it is likely that the major strong earthquakes occur on the southeast segment.

To sum up, we can speculate that this earthquake swarm occurred in the inactive period and it is related to the Wenchuan earthquake in 2008 and the Lushan earthquake in 2013. The occurrence of this earthquake swarm indicates the seismic activity on Xianshuihe fault may enter into a new active period in future. The risk of the strong earthquake in the southeast is higher than that in the northwest in future.

\section{Coulomb failure stress change of the historical earthquakes}

The Kangding $M_{\mathrm{S}} 6.3$ earthquake in 2014 is the first earthquake larger than M6.0 on the Xianshuihe fault since the Daofu $M_{\mathrm{S}} 6.9$ earthquake in 1981. Since 1700, almost all the segments of the Xianshuihe fault have been ruptured by the strong earthquake larger than M7.0 (Wen et al. 2008; Cheng et al. 2011a). Especially since the $M 7^{1} / 4$ earthquake in 1893 , six earthquakes with magnitude larger or near 7.0 ruptured the Xianshuihe fault, among which the $M 7.0$ earthquake in 1904 and $M_{\mathrm{S}} 6.9$ earthquake on the same fault segment (Fig. 9a). As to the only two segments without being ruptured since 1893, the segment on the south end of the Xianshuihe fault was stroked by the $M 7 \% / 4$ in 1786 , with the occurrence interval of more than 360 years (Cheng et al. 2011a), while the other one is the Selaha segment with $\sim 40 \mathrm{~km}$ length and not considerable earthquakes since 
(a)
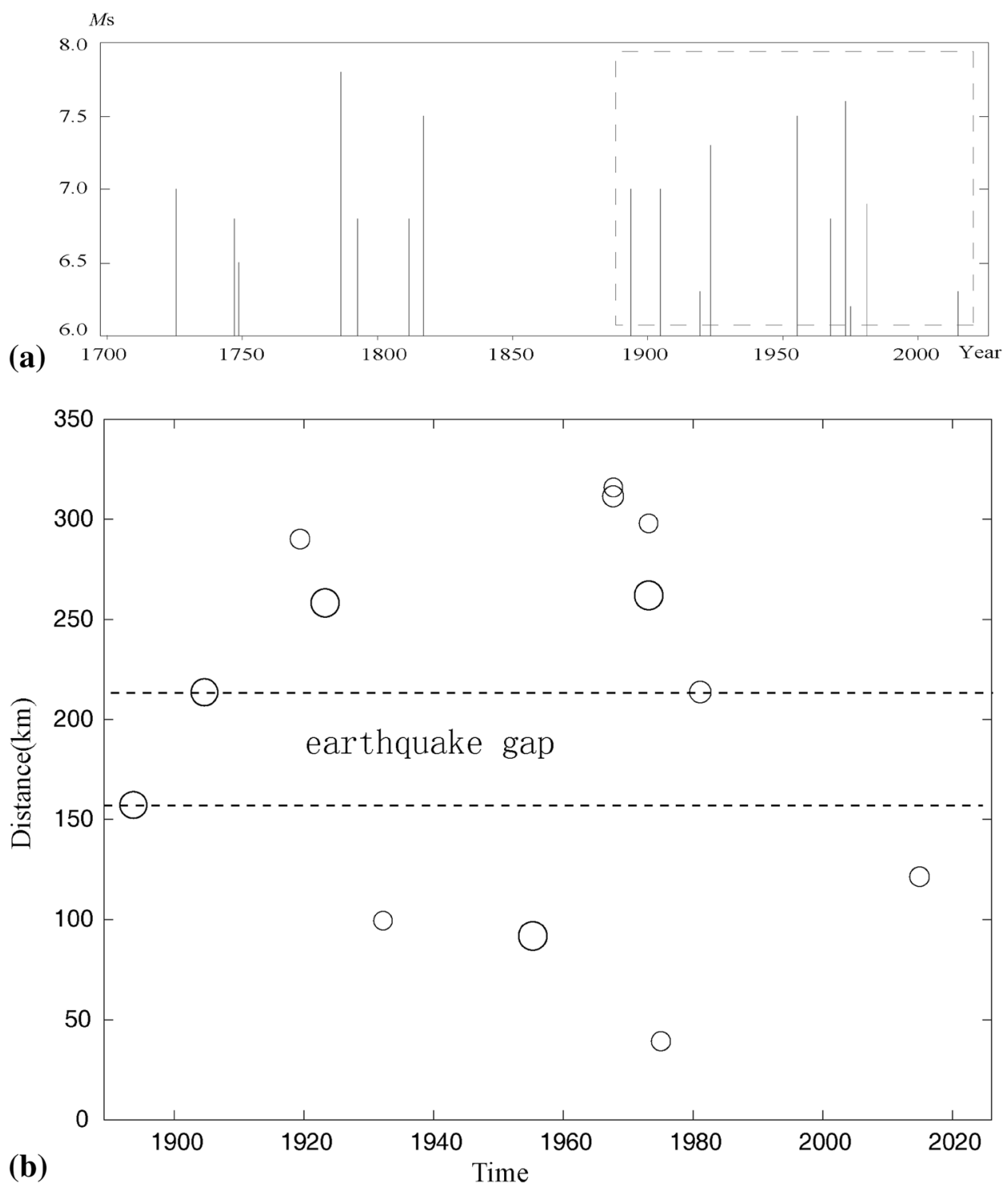

Fig. 7 The seismic activity of strong earthquake on the Xianshuihe fault a The magnitude of the historical earthquake above $M_{\mathrm{S}} 6.0$ since 1700 b the occurrence times of the historical earthquakes above $M_{S} 6.0$ versus the along-strike distances since 1893

1700. The $M_{\mathrm{S}} 6.3$ Kangding earthquake in 2014 just stroked the Selaha segment, although not ruptured the whole segment. Here, we have calculated the viscoelastic coulomb stress changes $(\triangle \mathrm{CFS})$ of the former historical earthquakes since 1893 on the rupture plane of the $M_{\mathrm{S}} 6.3$ Kangding earthquake in 2014 using the PSGRN/PSCMP code (Wang et al. 2006). In the calculation, the parameters of the historical earthquakes on the Xianshuihe fault are listed in Table 1. And the receiver fault in the Coulomb stress changes is the rupture segment of the Kangding earthquake, with strike of $145^{\circ}$, dip of $78^{\circ}$, and rake of $-11^{\circ}$.

We calculated the normal, shear, and coulomb stress changes on rupture segment of the Kangding earthquake from the historical earthquakes listed in Table 1. The Coulomb stress change, $\triangle \mathrm{CFS}$, is given by

$\Delta \mathrm{CFS}=\Delta \tau-\mu^{\prime} \Delta \sigma_{n}$,

where $\Delta \tau$ and $\Delta \sigma_{n}$ are the shear and normal stress changes on the fault plane; $\mu^{\prime}$ is the effective friction coefficient, taken to be 0.4 (Stein 1999).

As occurred in the region near the epicenter of the $M_{\mathrm{W}} 7.9$ Wenchuan earthquake in 2008 and $M_{\mathrm{W}} 6.6$ Lushan earthquake in 2013 , the $M_{\mathrm{S}} 6.3$ Kangding earthquake in 2014 should be affected by the stress changes from the two former earthquakes. Liu et al. (2014) published the calculation results of the coulomb stress changes, which show 

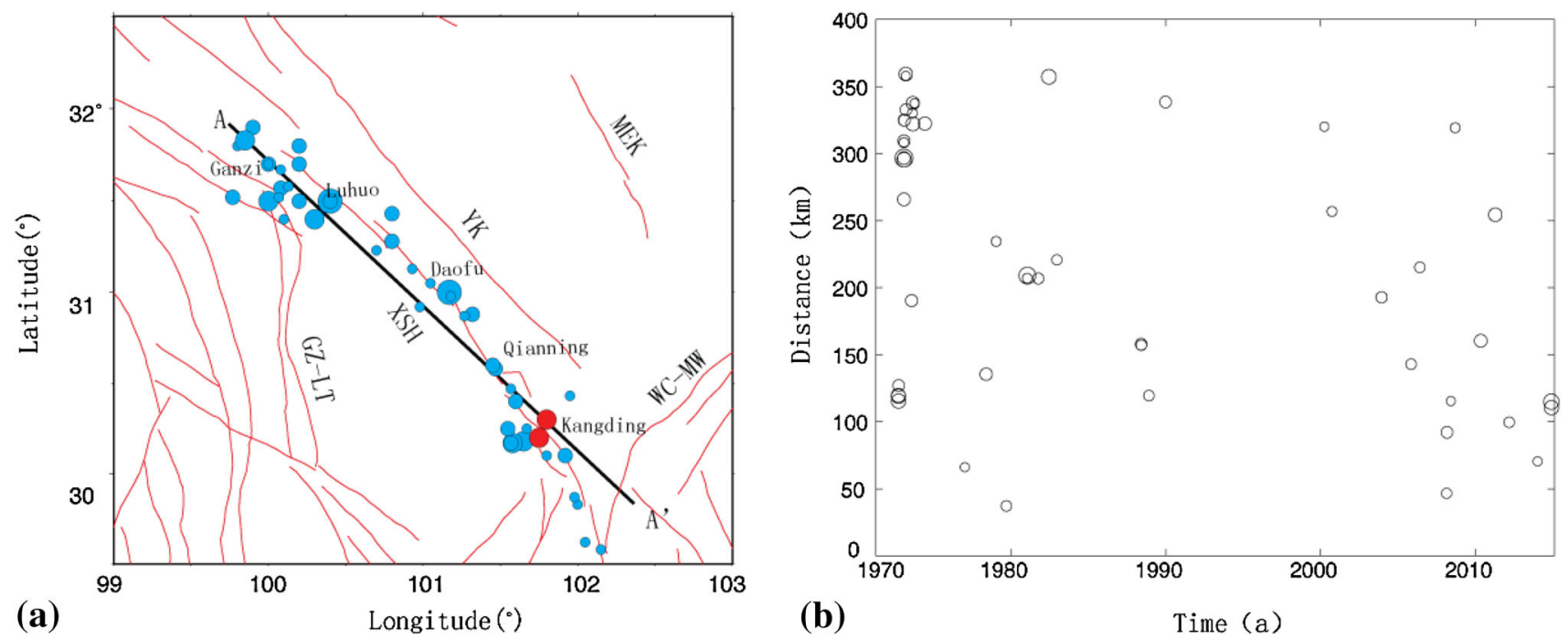

Fig. 8 The moderate earthquakes $\left(M_{\mathrm{L}} \geq 4\right.$.0) distribution along Xianshuihe fault a The distribution of the historical earthquakes above $M_{\mathrm{L}} 4.0$ since 1970 , the blue circles represent the historical earthquakes, the red ones represent the $M_{\mathrm{S}} 6.3$ and $M_{\mathrm{S}} 5.8$ Kangding earthquakes. The red lines represent the fault in the region. XSH, Xianshuihe fault, GZ-LT, Garzê-Litang fault, WC-MW, Wenchuan-Maowen fault, YK, Yuke fault, MEK, Maerkang fault b The occurrence times of the historical earthquakes above $M_{\mathrm{L}} 4.0$ versus the along-strike distances since 1970
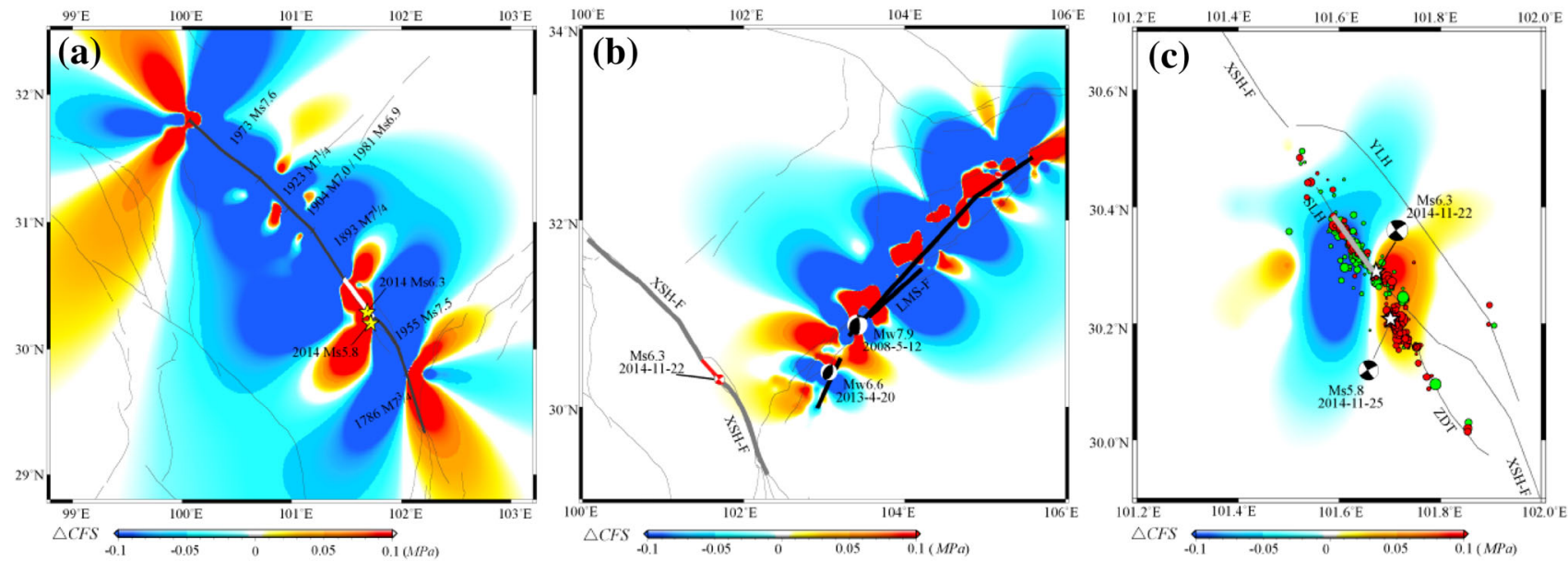

Fig. 9 a Calculated viscoelastic coulomb stress changes of the historical earthquakes on the fault plane of the $M_{\mathrm{S}} 6.3$ Kangding earthquake. Gray thin lines are the rupture segments of the historical earthquakes since 1893. The white line is the fault segment on the Xianshuihe fault with no rupture events since 1700. Yellow stars show the epicenter of the $M_{\mathrm{S}} 6.3$ and $M_{\mathrm{S}} 5.8$ recent earthquakes in 2014. b calculated Static coulomb stress changes of the $M_{\mathrm{W}} 7.9$ Wenchuan earthquake and $M_{\mathrm{W}} 6.6$ Lushan earthquake on the fault plane of the $M_{\mathrm{S}} 6.3$ Kangding earthquake. Black thick lines are the rupture plane of the $M_{\mathrm{W}} 7.9$ Wenchuan earthquake and $M_{\mathrm{W}} 6.6$ Lushan earthquake. Gray thick lines are the rupture segments of the historical earthquakes since 1893 on the Xianshuihe fault. Red thick line is the fault segment on the Xianshuihe fault with no rupture events since 1700. Focal mechanisms of the earthquakes are from Global CMT catalog. XSH-F, the Xianshuihe fault; LMS-F, the Longmenshan fault. c calculated static coulomb stress changes on the fault plane of the $M_{\mathrm{S}} 5.8$ on $25 \mathrm{Nov} 2014$; Beach balls are the focal mechanisms of the $M_{\mathrm{S}} 6.3$ and $M_{\mathrm{S}} 5.8$ earthquakes. Gray thick lines is the rupture plane of the $M_{\mathrm{S}} 6.3$ earthquake. Green circles are the aftershocks before the $M_{\mathrm{S}} 5.8$ occurred, while the red ones are the aftershocks after the $M_{\mathrm{S}} 5.8$ occurred. XSH-F, the Xianshuihe fault; YLH, the Yalahe branch fault; SLH, the Selaha branch fault; ZDT, the Zheduotang branch fault

that the stress of the Xianshuihe fault has increased after the Wenchuan earthquake and Lushan earthquake, but highly less than the failure stress lower by the historical earthquakes on the Xianshuihe fault, all the segment of which has been ruptured by historical events. Wang et al.
(2014) have calculated the coulomb stress changes of the Wenchuan earthquake and the Lushan earthquake, showing that the earthquake potential on the Xianshuihe fault is slightly increased. Hence, we also calculated the $\triangle \mathrm{CFS}$ of the Wenchuan earthquake and Lushan earthquake on the 
Table 1 Parameters of the ruptured event on the Xianshuihe fault since 1893 (modified from Cheng et al. 2011b)

\begin{tabular}{llllllll}
\hline Occurred date & $M_{\mathrm{W}}$ & Strike $\left(^{\circ}\right)$ & Dip $\left(^{\circ}\right)$ & Rake $\left(^{\circ}\right)$ & Length $(\mathrm{km})$ & $\begin{array}{l}\text { Width } \\
(\mathrm{km})\end{array}$ & Slip $(\mathrm{m})$ \\
\hline $1893-08-29$ & 7.1 & 150 & 90 & 0 & 54 & 15 & 2.06 \\
$1904-08-30$ & 6.85 & 135 & 90 & 0 & 33 & 15 & 1.42 \\
$1923-03-24$ & 7.0 & 132 & 90 & 0 & 45 & 15 & 1.75 \\
$1955-04-14$ & 7.25 & 141 & 90 & 0 & 64 & 15 & 2.92 \\
$1973-02-06$ & 7.32 & 131 & 90 & 0 & 73 & 15 & 3.26 \\
$1981-01-23$ & 6.55 & 135 & 90 & 0 & 33 & 15 & 0.51 \\
\hline
\end{tabular}

Table 2 Parameters of the crust and mantle used (Cheng et al. 2014)

\begin{tabular}{llllllll}
\hline No. & Layer & Width $(\mathrm{km})$ & $v_{\mathrm{P}}\left(\mathrm{km} \mathrm{s}^{-1}\right)$ & $v_{\mathrm{S}}\left(\mathrm{km} \mathrm{s}^{-1}\right)$ & $G / \mathrm{Pa}$ & $\eta /(\mathrm{Pa} \mathrm{s})$ & $\rho\left(\mathrm{g} \mathrm{cm}^{3}\right)$ \\
\hline 1 & Upper crust & 20 & 5.97 & 3.44 & $4.0 \times 10^{10}$ & $1.0 \times 10^{21}$ & 2700 \\
2 & Middle crust & 18 & 6.25 & 3.61 & $4.0 \times 10^{10}$ & $6.3 \times 10^{18}$ & 2800 \\
3 & Lower crust & 8 & 6.4 & 3.70 & $5.0 \times 10^{10}$ & $6.3 \times 10^{18}$ & 3000 \\
4 & Upper mantle & 1000 & 8.2 & 4.734 & $6.5 \times 10^{10}$ & $1.0 \times 10^{20}$ & 3320 \\
\hline
\end{tabular}

In which, $v_{\mathrm{P}}$ and $v_{\mathrm{S}}$ are the velocity of $\mathrm{P}$ wave and $\mathrm{S}$ wave, respectively. $G$ is the shear modulus. $\eta$ is the viscosity coefficient. $\rho$ is the density of each layer

fault plane of the Kangding $M_{\mathrm{S}} 6.3$ earthquake. And we have calculated the $\triangle \mathrm{CFS}$ of the $M_{\mathrm{S}} 6.3$ on the following $M_{\mathrm{S}} 5.8$ to illustrate the interactions of the two earthquakes. In our calculation, the parameters of each layer in Table 2 are from Cheng et al. (2014) in the study of nearby Ludian $M_{\mathrm{S}} 6.5$ earthquake in 2014. And the coseismic displacements of the rupture fault planes of the $M_{\mathrm{W}} 7.9$ Wenchuan earthquake in 2008 and the $M_{\mathrm{W}} 6.6$ Lushan earthquake in 2013 are from Wang et al. (2008) and Wang et al. (2013), respectively. While the rupture parameters of the $M_{\mathrm{S}} 6.3$ earthquake are from the aftershock distribution data, with length of $12 \mathrm{~km}$, width of $13 \mathrm{~km}$ as the depth $5-18 \mathrm{~km}$, the average displacement is about $0.24 \mathrm{~m}$, and the seismic moment is $1.14 \times 10^{18}$ $\mathrm{N}$ m equivalent to an $M_{\mathrm{W}} 6.0$ earthquake. Figure $9 \mathrm{a}$ shows the viscoelastic $\triangle \mathrm{CFS}$ of the historical events on the $M_{\mathrm{S}} 6.3$ Kangding earthquake. The results show the $\triangle \mathrm{CFS}$ on the Selaha segment was increased by the historical events with the value on the epicenter $\left(30.3^{\circ} \mathrm{N}\right.$, $101.7^{\circ} \mathrm{E}$ ) of about $1.13 \mathrm{MPa}$, which is great enough to trigger an earthquake. And the $\triangle \mathrm{CFS}$ on the segment of the $M 7^{1 / 4}$ earthquake ruptured was also increased by the coulomb stress changes after the historical events, the maximum value of $0.45 \mathrm{MPa}$.

Figure $9 \mathrm{~b}$ shows the $\triangle \mathrm{CFS}$ of the $M_{\mathrm{W}} 7.9$ Wenchuan earthquake in 2008 and the $M_{\mathrm{W}} 6.6$ Lushan earthquake in 2013 on the fault plane $M_{\mathrm{S}} 6.3$ Kangding earthquake. The $\triangle \mathrm{CFS}$ value is about $0.011 \mathrm{MPa}$ at the epicenter of the $M_{\mathrm{S}} 6.3$ Kangding earthquake, larger than the threshold of the 0.01 MPa to trigger an earthquake (Stein 1999). And the $\Delta$ CFS of the $M_{\mathrm{S}} 6.3$ earthquake on the $M_{\mathrm{S}} 5.8$ in Fig. $9 \mathrm{c}$ shows that the $M_{\mathrm{S}} 5.8$ earthquake on the Zheduotang branch fault is triggered by the former $M_{\mathrm{S}} 6.3$ earthquake, even the aftershocks of the $M_{\mathrm{S}} 5.8$ are in the areas where the $\Delta$ CFS increased.

The Selaha branch fault, where the $M_{\mathrm{S}} 6.3$ Kangding earthquake occurred, is one of the three branch faults of the Selaha segment on the Xianshuihe fault. The whole slip rate of the segment may distribute on the three branch faults. The energy accumulation on each branch fault is not as fast as that on other segment. This may be the reason why the three branch faults of the Selaha segment have not ruptured entirely since 1893 , although promoted by the $\triangle \mathrm{CFS}$ on the other segments on the Xianshuihe fault with large earthquakes. In our calculation of the viscoelastic $\Delta \mathrm{CFS}$, the historical events have a positive impact on the Selaha segment where the $M_{\mathrm{S}} 6.3$ Kangding earthquake occurred with the $\triangle \mathrm{CFS}$ value of about $1.13 \mathrm{MPa}$. This value is much larger than the one from the Wenchuan earthquake and Lushan earthquake of 0.11 MPa.

We also stated the time process of the $\triangle \mathrm{CFS}$ in history. Figure 10 shows the $\Delta$ CFS on the epicenter of the $M_{S} 6.3$ Kangding earthquake caused by the historical earthquakes since 1893 . It is obviously that the $M_{\mathrm{S}} 7.5$ earthquake in 1955 played an important role on triggering the $M_{\mathrm{S}} 6.3$ Kangding earthquake. The $\triangle \mathrm{CFS}$ reaches to $0.843 \mathrm{MPa}$ which is much greater than other historical earthquakes nearby. The 12 May $2008 M_{\mathrm{W}} 7.9$ Wenchuan earthquake and the 20 April $M_{\mathrm{W}} 6.6$ Lushan earthquake were the most significant earthquakes in Sichuan region recently. They also contributed to the occurrence of the Kangding earthquake. The $\triangle \mathrm{CFS}$ triggering by the Wenchuan earthquake was only $0.01 \mathrm{MPa}$. The $\triangle \mathrm{CFS}$ caused by the Lushan earthquake was much smaller. 


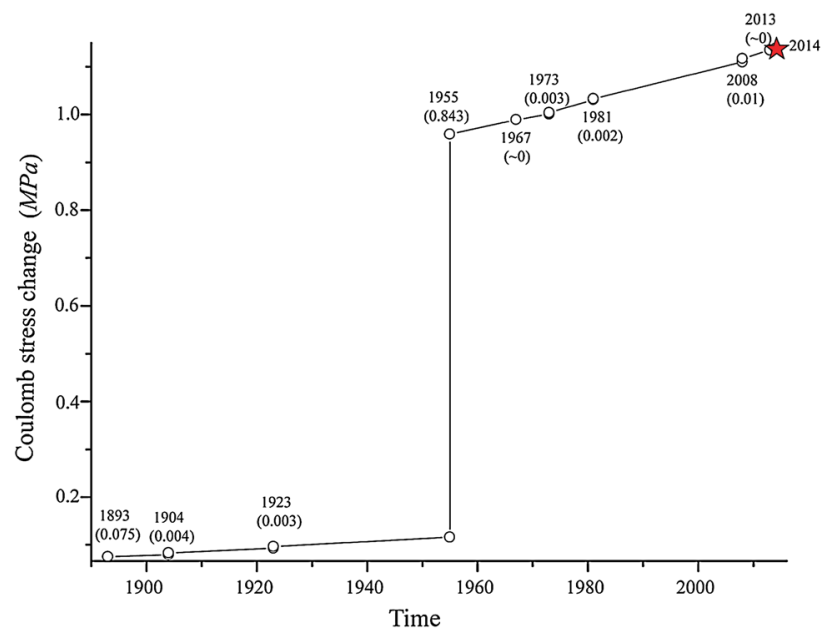

Fig. 10 Viscoelastic Coulomb stress changes on the epicenter of the $M_{\mathrm{S}} 6.3$ Kangding earthquake in 2014 since 1893

\section{Discussion and conclusions}

There were only two earthquake swarms on Xianshuihe fault since 1970, including this Kangding November, 2014 swarm and the earthquake swarm in 1972. It may be related to the Cenozoic granite which is considered to be fractured and can hardly store up the energy. It is a noteworthy issue for the particularity of the Kangding earthquake swarm. In this article, we have analyzed the tectonic setting of Xianshuihe fault, the focal mechanism, the Kangding earthquake sequence, the migration of the historical earthquakes, and the coulomb failure stress change.

From the distribution and the parameters of the swarm in 2014, the Kangding earthquake sequence extends northwest whose major axis is about $47 \mathrm{~km}$ and minor axis is about $13 \mathrm{~km}$. The length of the $M_{\mathrm{S}} 6.3$ 's aftershock zone is about $25 \mathrm{~km}$, while the length of the $M_{\mathrm{S}} 5.8$ 's is about $14 \mathrm{~km}$. Before the $M_{\mathrm{S}} 5.8$ earthquake occurred, the $b$ value of the sequence is lower than the average of that on Xianshuihe fault. Nevertheless, the $b$ value rises to be higher than the average of that on Xianshuihe fault after the occurrence of the $M_{\mathrm{S}} 5.8$ earthquake. The $h$ values in different periods show the aftershocks of the $M_{\mathrm{S}} 6.3$ earthquake decayed more rapidly than the aftershocks of the $M_{\mathrm{S}} 5.8$ earthquake. The results of the parameters show the lower stress level in the region and the stress relaxation after the second earthquake is more than the first one.

For the migration of the historical earthquakes, the earthquakes above $M_{\mathrm{S}} 6.0$ on the Xianshuihe fault occurred frequently since 1893 . The Kangding $M_{\mathrm{S}} 6.3$ earthquake located on the southeast of the earthquake gap in the Xianshuihe fault. The earthquakes above $M_{\mathrm{S}} 6.0$ occurred alternately in the southeast and the northwest part of the Xianshuihe fault. It is the first earthquake above $M_{\mathrm{S}} 6.0$ that occurred on Xianshuihe fault since 1981. The earthquake swarm occurred in the inactive period on Xianshuihe fault. This earthquake swarm is related to the Wenchuan earthquake in 2008 and the Lushan earthquake in 2013. Because the enhance seismicity of the moderate-strong earthquakes on the southeast segment, we should focus on the possibility of the major strong earthquake on the area.

As to the swarm in 2014, our coulomb stress change calculation shows that the later $M_{\mathrm{S}} 5.8$ earthquake is triggered by the former $M_{\mathrm{S}} 6.3$ earthquake, although some errors in the calculation may be caused by the rupture model of the main earthquake, crustal model, and the slip behavior of the received fault. Our results, using the parameters from the aftershock distribution to calculate the coulomb stress changes, may be the most appropriate method to decrease the errors. The earthquake swarm located on the affected zone of the historical earthquakes' stress triggering since 1893 , especially by the Kangding $M_{\mathrm{S}} 7.5$ in 1955. We think the Selaha branch fault, where the stable energy accumulation from the fault slip motion and the promotion from historical events on other neighboring segments are able to generate an $M_{\mathrm{S}} 6.3$ earthquake but not enough to rupture the entire segment. Using the focal mechanisms of these two earthquakes, our results also show that the $M_{\mathrm{S}} 6.3$ earthquake was advanced by the historical earthquakes on the other segments of the Xianshuihe fault and the recent Wenchuan $M_{\mathrm{S}} 8.0$ earthquake and Lushan $M_{\mathrm{S}} 7.0$ earthquake.

Based on the above analysis, we can draw the conclusions as below:

(1) The Kangding $M_{\mathrm{S}} 6.3$ and $M_{\mathrm{S}} 5.8$ earthquakes occurred in the Selaha segment on the Xianshuihe fault which contains three fault branches. They are both sinistral slip events with NW direction.

(2) The stress level may reduce in the region after the $M_{\mathrm{S}} 5.8$ earthquake for the rapid release of energy.

(3) The occurrence of this earthquake swarm indicates the seismic activity on the Xianshuihe fault may be in a relatively inactive period. The major strong earthquake on the area should be concerned in the future.

(4) The stress transfer caused by the historical earthquakes increases the stress accumulation on this segment, and encourages the occurrence of these two earthquakes. The subsequent $M_{\mathrm{S}} 5.8$ earthquake was triggered by the $M_{\mathrm{S}} 6.3$ earthquake.

Acknowledgments This work was supported by Spark Program of Earthquake Science of China under Grant No. XH15047Y and National Natural Science Foundation of China under Grant No. 41274062 .

Open Access This article is distributed under the terms of the Creative Commons Attribution 4.0 International License (http://creativecommons.org/licenses/by/4.0/), which permits unrestricted use, 
distribution, and reproduction in any medium, provided you give appropriate credit to the original author(s) and the source, provide a link to the Creative Commons license, and indicate if changes were made.

\section{References}

Allen CR, Luo Z, Qian H, Wen X, Zhou H, Huang W (1991) Field study of a highly active fault zone: the Xianshuihe fault of southwestern China. Geol Soc Am Bull 103:1178-1199

Cheng J, Liu J, Gan WJ, Yu HZ (2011a) Coulomb stress interaction among strong earthquakes around the Bayan Har block since the Manyi earthquake in 1997. Chin J Geophys 54:1997-2010 (in Chinese with English abstract)

Cheng J, Liu J, Gan WJ, Yu HZ, Li G (2011b) Characteristics of strong earthquake evolution around the eastern boundary faults of the Sichuan-Yunnan rhombic block. Sci China Earth Sci 54:1716-1729. doi:10.1007/s11430-011-4290-2

Cheng J, Liu J, Xu XW, Gan WJ (2014) Tectonic characteristics of strong earthquakes in Daliangshan sub-block and impact of the Ms6.5 Ludian earthquake in 2014 on the surrounding faults. Seismol Geol 36(4):1228-1243 (in Chinese with English abstract)

China earthquake networks center. http://www.ceic.ac.cn/speed search?time $=10 /$, November 2014

Deng QD, Gao X, Chen GH, Yang H (2010) Recent tectonic activity of Bayankala fault-block and the Kunlun-Wenchuan earthquake series of the Tibetan Plateau. Earth Sci Front 17:163-178 (in Chinese with English abstract)

Gan W, Zhang P, Shen ZK, Niu Z, Wang M, Wan Y, Zhou D, Cheng J (2007) Present-day crustal motion within the Tibetan Plateau inferred from GPS measurements. J Geophys Res. doi:10.1029/ 2005JB004120

Han WB, Huang SM (1983) A seismic gap on the Xianshuihe fault, Sichuan province. Acta Seismol Sin 5(3):280-286 (in Chinese with English abstract)

Lin BH, Cheng TC, Pu XH, Liu WQ, Peng MX, Zhang WP (1986) Ruptrure processes of strong earthquakes on Xianshuihe fault belt and seismic activity. Acta Seismol Sin 8(1):1-20

Liu M, Luo G, Wang H (2014) The 2013 Lushan earthquake in China tests hazard assessments. Seismol Res Lett. doi:10.1785/ 0220130117

Mogi K (1962) Study of elastic shocks caused by the fracture of heterogeneous materials and its relatives to earthquake phenomena. Bull Earthq Res Inst, Tokyo Univ 40:125-174
Omori F (1894) On the aftershocks of earthquake. J Coll Sci Imp, Tokyo univ 7:111-200

Stein RS (1999) The role of stress transfer in earthquake occurrence. Nature 402:605-609. doi:10.1038/45144

Tang RC and Huang ZZ (1983). The basic seismo-geological characteristics of the Xianshuihe fracture zone and the current situation of research thereon. Recent Dev World Seismol 3 (1-4). (in Chinese with English abstract)

USGS. http://earthquake.usgs.gov/earthquakes/, November 2014

Utsu T (1961) A statistical study on the occurrence of aftershocks. Geophys Mag 30:521-605

Wang BQ, Wang CZ (1983) Temporal and spatial features of aftershock sequences. Acta Seismol Sin 5(4):383-396

Wang RJ, Lorenzo-Martín F, Roth F (2006) PSGRN/PSCMP-a new code for calculating co- and post-seismic deformation, geoid and gravity changes based on the viscoelastic-gravitational dislocation theory. Comput Geosci 32(4):527-541

Wang WM, Zhao LF, Li J, Yao ZX (2008) Rupture process of the $M_{\mathrm{S}} 8.0$ Wenchuan earthquake of Sichuan, China. Chin J Geophys 51(5):1403-1410 (in Chinese with English abstract)

Wang WM, Hao JL, Yao ZX (2013) Preliminary result for rupture process of April 20, 2013, Lushan earthquake, Sichuan, China. Chin J Geophys 56(4):1412-1417 (in Chinese with English abstract)

Wang Y, Wang F, Wang M, Shen Z, Wan Y (2014) Coulomb stress change and evolution induced by the 2008 Wenchuan earthquake and its delayed triggering of the $2013 \quad M_{\mathrm{W}} 6.6$ Lushan earthquake. Seismol Res Lett. doi:10.1785/0220130111

Wen XZ (1989) Segmentation, Geometric features, and their seimotectonic implications for the Holocene Xianshuihe fault zone. Acta Seismol Sin 11:360-370 (in Chinese with English abstract)

Wen XZ (2000) Character of rupture segmentation of the XianshuiheAnninghe-Zemuhe fault zone, Western Sichuan. Seismol Geol 22:239-249 (in Chinese with English abstract)

Wen XZ, Ma SL, Xu XW (2008) Historical pattern and behavior of earthquake ruptures along the eastern boundary of the SichuanYunnan faulted-block, southwestern China. Phys Earth Planet Inter 168:16-36

Xu X, Wen X, Zheng R, Ma W, Song F, Yu G (2003) Pattern of latest tectonic motion and its dynamics for active blocks in SichuanYunnan region. China. Sci China Ser D-Earth Sci 46:210-226

Zhang PZ, Deng QD, Zhang GM, Ma J, Gan WJ, Min W, Mao FY, Wang Q (2003) Active tectonic-block and Strong earthquakes in the continent of China. Sci China Ser. D-Earth Sci 46:13-20 